\title{
Simultaneous Quantitative Determination of Six Caffeoylquinic Acids in Matricaria chamomilla L. with High-Performance Liquid Chromatography
}

\author{
Yifan Zhao $\mathbb{D}^{D}$, Peng Sun $\mathbb{D}^{D}$, Yue Ma $\mathbb{D}^{D}$, Kun Wang $\mathbb{D}^{D}$, Xiaoqiang Chang $\mathbb{D}$, Yue Bai $\mathbb{D}$, \\ Dong Zhang $(\mathbb{D}$, and Lan Yang $\mathbb{1}$ \\ Artemisinin Research Center and Institute of Chinese Materia Medica, China Academy of Chinese Medical Sciences, \\ Beijing 100700, China \\ Correspondence should be addressed to Dong Zhang; dzhang@icmm.ac.cn and Lan Yang; lyang@icmm.ac.cn
}

Received 12 April 2019; Revised 13 August 2019; Accepted 9 September 2019; Published 3 November 2019

Academic Editor: Artur M. S. Silva

Copyright (c) 2019 Yifan Zhao et al. This is an open access article distributed under the Creative Commons Attribution License, which permits unrestricted use, distribution, and reproduction in any medium, provided the original work is properly cited.

\begin{abstract}
A simple and effective method for the simultaneous quantitative analysis of six caffeoylquinic acids (CAs) in Matricaria chamomilla L. (M. chamomilla) using high-performance liquid chromatography (HPLC) with diode-array detection (DAD) was established. The chromatographic separation was performed on a Waters XBridge Shield RP $\mathrm{C}_{18}$ column $(4.6 \mathrm{~mm} \times 250 \mathrm{~mm}$, $5 \mu \mathrm{m})$ with the mobile phase of acetonitrile $(0.5 \%$ phosphoric acid) and water $(0.5 \%$ phosphoric acid $)$ using a gradient elution at a flow rate of $1.0 \mathrm{~mL} / \mathrm{min}$ and UV detection at $327 \mathrm{~nm}$. The correlation coefficients of all analytes were 0.999 , and the results showed excellent linearity. The lower limits of detection (LLOD) and quantification (LLOQ) of all analytes fall within the range of $0.014 \sim 0.017 \mu \mathrm{g} / \mathrm{mL}$ and $0.068 \sim 0.086 \mu \mathrm{g} / \mathrm{mL}$, respectively. The extraction recoveries of all analytes fall within the range of $100.74 \% \sim$ $101.55 \%$, with relative standard deviation not exceeding $2.83 \%$. The intraday and interday precisions fall within the range of $0.03 \% \sim 0.65 \%$ and $0.02 \% \sim 0.09 \%$, respectively. This validated method was successfully applied to the investigation of 34 samples of M. chamomilla collected from different geographical areas. The results showed that the established method is appropriate for the analysis of the six CAs in M. chamomilla and helpful for quality assessment of capitula of M. chamomilla (CMC), whole herb of M. chamomilla (WHMC), and related herbal formulas.
\end{abstract}

\section{Introduction}

Matricaria chamomilla L. (M. chamomilla) is a kind of famous herbaceous plant indigenous to Europe. It has been naturalized to many countries and regions of the world for thousands of years as one of the most popular medicinal plants in folk and traditional medicine $[1,2]$. The capitula of M. chamomilla (CMC), named as "German Chamomile" in Europe, is included in the United States Pharmacopoeia (USP), European Pharmacopoeia (EP), and British Pharmacopoeia $(B P)$ to treat a series of diseases, such as digestive ailments, restlessness, mild insomnia due to nervous disorders, inflammation, and irritations of the skin and mucosa [3]. The dried whole herb of M. chamomilla (WHMC) named as "Yangganju" is recorded in Medicine and Pharmacy of Traditional Uyghur Medicine in Xinjiang China to treat stomach upset, dysuria, skin itching, blurred vision, cystitis, and stomatitis [4]. Moreover, essential oil of $M$. chamomilla is used extensively in cosmetics and aromatherapy in Europe [5]. In sight of its significant therapeutic applications, a large group of active constituents have been identified from M. chamomilla by researchers [6-9]. Our group has been devoted to the study on potential bioactive natural products in traditional medicinal plants for several decades [10-13]. In our previous chemical constituent study of M. chamomilla, except chlorogenic acid, five other caffeoylquinic acids (neochlorogenic acid, cryptochlorogenic acid, and isochlorogenic acid A, B, and C) were identified from $M$. chamomilla for the first time (Figure 1). The CAs represent a class of interesting natural products with wide pharmacological activities including antioxidant [14], anti-inflammatory [15, 16], antimicrobial [17], enzyme inhibition [18], 

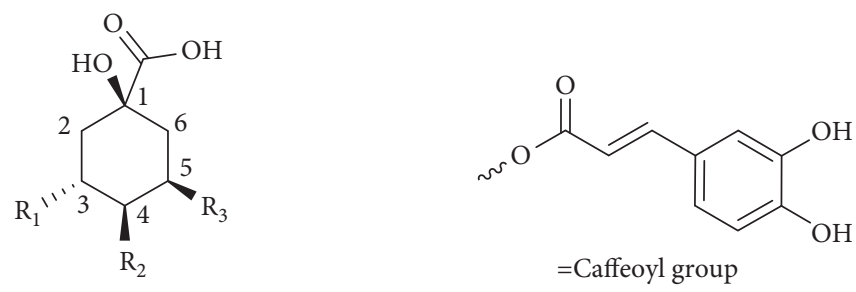

\begin{tabular}{lcccc}
\hline Substance & Abbreviation & $\mathrm{R}_{1}$ & $\mathrm{R}_{2}$ & $\mathrm{R}_{3}$ \\
\hline Neochlorogenic acid & NCA & OH & OH & Caffeoyl \\
Cryptochlorogenic acid & CCA & OH & Caffeoyl & OH \\
Chlorogenic acid & CA & Caffeoyl & OH & OH \\
Isochlorogenic acid A & ICA & Caffeoyl & OH & Caffeoyl \\
Isochlorogenic acid B & ICB & Caffeoyl & Caffeoyl & OH \\
Isochlorogenic acid C & ICC & OH & Caffeoyl & Caffeoyl \\
\hline
\end{tabular}

Figure 1: Chemical structures of six CAs.

hepatocyte protection [19], platelet aggregation inhibition [20], antihepatic fibrosis [21], and anti-SARS [22]. According to these previous reports, the pharmacological activities of CAs were consistent with the efficacy of CMC and WHMC, and thus, the CAs should be the active ingredients. However, the method for the determination of CAs in M. chamomilla has not been reported. Herein, to develop improved solution for the quality evaluation of CMC and WHMC, a simple and effective HPLC method was developed for simultaneous quantitative analyses of the six CAs.

\section{Experimental}

2.1. Chemicals, Reagents, and Materials. Acetonitrile (HPLC grade) was purchased from Fisher (Canada). Phosphoric acid (HPLC grade) was purchased from CNW Technology (Germany). Purified water was purchased from Wahaha Company (China). Syringe filter $(0.45 \mu \mathrm{m})$ was purchased from ANPEL (China). Standard compounds of neochlorogenic acid (NCA), cryptochlorogenic acid (CCA), and isochlorogenic acid A, B, and $C$ (ICA, ICB, and ICC) were purchased from Chengdu Herbpurify CO., LTD. Standard compound of chlorogenic acid (CA) was purchased from National Institutes for Food and Drug Control. The purity of the six reference compounds was determined to be more than $98 \%$ by normalization of the peak areas detected by HPLC-DAD.

A total of 34 samples were collected from different geographical areas and identified as Matricaria chamomilla (L.) by Professor Chunsheng Liu and his group at Beijing University of Chinese Medicine, as shown in Table 1. The samples were airdried (indoor) at the origin of collection. Among them, 3 representative geographical batches (D1, D10, and D12) were categorized into different parts of $M$. chamomilla (roots, stems, and leaves) in the laboratory. These medicinal materials were deposited in Institute of Chinese Materia Medica, China Academy of Chinese Medical Sciences.
2.2. Apparatus. All medicinal materials were ground by high-speed disintegrator (Tianjin Taisite FW100). All sample extraction processes were carried out in a water bath (Tianjin Taisite DK-98-1). All medicinal materials and standard compounds were weighed by electronic analytical balances (Mettler Toledo AL204-IC and XS105 Dual Range). The HPLC system was SHIMADZU Prominence LC-20A (Shimadzu Corporation, Tokyo, Japan) equipped with CBM20Alite system controller, LC-20AT pump, CTO-20A column oven, SPD-M20A UV-Vis detector, SIL-20A autoinjector, DGU-M20A 5 degasser, and Shimadzu LC-solution work station.

2.3. Chromatographic Conditions. The separation of CAs was carried out on a Waters XBridge Shield RP $\mathrm{C}_{18}$ column $(4.6 \mathrm{~mm} \times 250 \mathrm{~mm}, 5 \mu \mathrm{m})$ at $35^{\circ} \mathrm{C}$ with a flow rate of $1.0 \mathrm{~mL} /$ min. The detection wavelength was $327 \mathrm{~nm}$ with an injection volume of $10 \mu \mathrm{L}$. The optimized mobile phase system was A (acetonitrile/phosphoric acid, 99.5/0.5, v/v) and B (water/ phosphoric acid, 99.5/0.5, $v / v$ ) with a gradient elution program: $\mathrm{A} / \mathrm{B}=12 / 82(0-13 \mathrm{~min}), \mathrm{A} / \mathrm{B}=12 / 82-25 / 75$ (13$15 \mathrm{~min})$, and $\mathrm{A} / \mathrm{B}=25 / 75(15-30 \mathrm{~min})$. All data were acquired and processed by Shimadzu LC solution software.

2.4. Preparation of Standard Solution. Standards were weighed accurately and dissolved in $10 \mathrm{~mL}$ of $70 \%$ aqueous methanol to prepare the standard mix stock solution of NCA $(270 \mu \mathrm{g} / \mathrm{mL})$, CCA $(212 \mu \mathrm{g} / \mathrm{mL})$, CA $(240 \mu \mathrm{g} / \mathrm{mL}), \quad$ ICA $(260 \mu \mathrm{g} / \mathrm{mL}), \mathrm{ICB}(218 \mu \mathrm{g} / \mathrm{mL})$, and ICC $(246 \mu \mathrm{g} / \mathrm{mL})$. The standard mix stock solution was stored at $4^{\circ} \mathrm{C}$ and filtered through a $0.45 \mu \mathrm{m}$ syringe filter before HPLC analysis.

2.5. Preparation of Sample Solution. A conical flask was charged with $0.3 \mathrm{~g}$ of sample and $15 \mathrm{~mL}$ of $70 \%$ aqueous methanol. Then, the sample was refluxed for $45 \mathrm{~min}$. After 
TABLE 1: Sample information of M. chamomilla collected from different geographical areas.

\begin{tabular}{|c|c|c|c|}
\hline Samples & Parts & Sources & Collection time \\
\hline D1 & WHMC & Tacheng County, Xinjiang Autonomous Region & March, 2016 \\
\hline D3 & WHMC & Hotan Prefecture, Xinjiang Autonomous Region & September 19,2016 \\
\hline D4 & WHMC & Jimsar County, Xinjiang Autonomous Region & September 19, 2016 \\
\hline D5 & WHMC & $\begin{array}{c}\text { Yili Kazakh Autonomous Prefecture, Xinjiang } \\
\text { Autonomous Region }\end{array}$ & February 17, 2017 \\
\hline D6 & WHMC & Huo Cheng County, Xinjiang Autonomous Region & March, 2017 \\
\hline D7 & WHMC & Tacheng County, Xinjiang Autonomous Region & March 23, 2017 \\
\hline D8 & WHMC & $\begin{array}{c}\text { Qapqal County, Yili Autonomous Prefecture, } \\
\text { Xinjiang Autonomous Region }\end{array}$ & March 23, 2017 \\
\hline D9 & WHMC & $\begin{array}{c}\text { Hospital of Xinjiang Traditional Uyghur Medicine, } \\
\text { Xinjiang Autonomous Region }\end{array}$ & April 07, 2017 \\
\hline D10 & WHMC & $\begin{array}{c}\text { Institute of Medicinal Plant Development, Sanming } \\
\text { City Academy of Agricultural Sciences, Fujian } \\
\text { Province }\end{array}$ & June 14, 2017 \\
\hline D11 & WHMC & $\begin{array}{l}\text { Xuancheng Yueping Ecological Technology } \\
\text { Development Co., Ltd., Anhui Province }\end{array}$ & June 14, 2017 \\
\hline D12 & WHMC & Beijing University of Chinese Medicine, Beijing & June 24, 2017 \\
\hline H1 & CMC & Tacheng County, Xinjiang Autonomous Region & March, 2016 \\
\hline $\mathrm{H} 2$ & $\mathrm{CMC}$ & Xinjiang Autonomous Region & September, 2017 \\
\hline H3 & $\mathrm{CMC}$ & Guangzhou, Guangdong Province & September, 2017 \\
\hline $\mathrm{H} 4$ & CMC & Qingdao, Shandong Province & September, 2017 \\
\hline H5 & $\mathrm{CMC}$ & Fuyang, Anhui Province & September, 2017 \\
\hline H6 & CMC & $\begin{array}{c}\text { Qapqal County, Yili Autonomous Prefecture, } \\
\text { Xinjiang Autonomous Region }\end{array}$ & September, 2017 \\
\hline $\mathrm{H7}$ & CMC & Tai'an, Shandong Province & September, 2017 \\
\hline $\mathrm{H} 8$ & $\mathrm{CMC}$ & $\begin{array}{l}\text { South of Xinjiang Autonomous Region } \\
\text { Germany import (grade 1), Woyang County }\end{array}$ & September, 2017 \\
\hline $\mathrm{H} 9$ & $\mathrm{CMC}$ & $\begin{array}{l}\text { Hongyang County Chinese Herbal Medicine Sales } \\
\text { Co., Ltd., Chongqing } \\
\text { Germany import (grade 2), Woyang County }\end{array}$ & September, 2017 \\
\hline $\mathrm{H} 10$ & $\mathrm{CMC}$ & $\begin{array}{c}\text { Hongyang County Chinese Herbal Medicine Sales } \\
\text { Co., Ltd., Chongqing }\end{array}$ & September, 2017 \\
\hline H11 & $\mathrm{CMC}$ & $\begin{array}{c}\text { Xuancheng, Anhui Province } \\
\text { Institute of Medicinal Plant Development, Sanming }\end{array}$ & September, 2017 \\
\hline $\mathrm{H} 12$ & $\mathrm{CMC}$ & $\begin{array}{c}\text { City Academy of Agricultural Sciences, Fujian } \\
\text { Province }\end{array}$ & June 14, 2017 \\
\hline H13 & $\mathrm{CMC}$ & Beijing University of Chinese Medicine, Beijing & May 13, 2017 \\
\hline H14 & $\mathrm{CMC}$ & Beijing University of Chinese Medicine, Beijing & July 20, 2017 \\
\hline D1 roots & Roots & Tacheng County, Xinjiang Autonomous Region & March, 2016 \\
\hline D1 stems & Stems & Tacheng County, Xinjiang Autonomous Region & March, 2016 \\
\hline D1 leaves & Leaves & $\begin{array}{l}\text { Tacheng County, Xinjiang Autonomous Region } \\
\text { Institute of Medicinal Plant Development, Sanming }\end{array}$ & March, 2016 \\
\hline D10 roots & Roots & $\begin{array}{c}\text { City Academy of Agricultural Sciences, Fujian } \\
\text { Province }\end{array}$ & June 14, 2017 \\
\hline D10 stems & Stems & $\begin{array}{c}\text { Institute of Medicinal Plant Development, Sanming } \\
\text { City Academy of Agricultural Sciences, Fujian } \\
\text { Province }\end{array}$ & June 14, 2017 \\
\hline D10 leaves & Leaves & $\begin{array}{c}\text { Institute of Medicinal Plant Development, Sanming } \\
\text { City Academy of Agricultural Sciences, Fujian } \\
\text { province }\end{array}$ & June 14, 2017 \\
\hline D12 roots & Roots & Beijing University of Chinese Medicine, Beijing & June 24, 2017 \\
\hline D12 stems & Stems & Beijing University of Chinese Medicine, Beijing & June 24, 2017 \\
\hline D12 leaves & Leaves & Beijing University of Chinese Medicine, Beijing & June 24, 2017 \\
\hline
\end{tabular}

Note. H1, D1, D1 roots, D1 stems, and D1 leaves were derived from D1; H10, D10, D10 roots, D10 stems, and D10 leaves were derived from D10; H13, H14, D12, D12 roots, D12 stems, and D12 leaves were derived from D12.

cooling to room temperature, replenish the loss of the solvent with $70 \%$ aqueous methanol. Finally, the sample solution was filtered through a $0.45 \mu \mathrm{m}$ syringe filter prior to HPLC analysis.
2.6. Method Validation. The proposed method was validated according to CFDA guidelines for the validation of analytical methods for pharmaceutical quality standard, with respect to linearity, lower limit of detection (LLOD) and 
quantification (LLOQ), precision, repeatability, stability, and accuracy.

The standard mix stock solutions at 12 different concentrations were injected for two replicates. The calibration curve was constructed by least square fit of the data with the peak area ( $y$-axis) versus the injection amounts ( $x$-axis) for each compound. The standard mix stock solution was further diluted to explore the LLOD and LLOQ. The LLOD and LLOQ were determined at a signal-to-noise $(S / N)$ ratio of 3 and 10, respectively.

The precision was evaluated with standard solution under the selected optimal conditions in six replicates continuously. To further evaluate the repeatability of the developed assay, the sample was analyzed in six replicates. Stability was tested with the sample at room temperature $\left(25^{\circ} \mathrm{C}\right)$ and analyzed at $0,4,12$, 24,48 , and $72 \mathrm{~h}$, respectively. Recovery tests were performed to evaluate the accuracy of the developed method. The accurate amounts of six CAs were weighed and spiked to certain amounts of the sample powder and were then extracted and analyzed in accordance with the method described above. The spiked amount of each standard was adjusted to provide a similar concentration present in the sample. The recovery rate (\%) was measured for six replicates.

\section{Results and Discussion}

3.1. Optimization of the Extraction Procedure. During sample preparation, the extraction parameters, e.g., extraction method, solvent, extraction time, and solvent volume, were optimized. The efficiency of the extraction procedure was evaluated using different extraction methods, i.e., reflux and ultrasonic-assisted method. The results demonstrated that the reflux method provided the higher value in the content of the target compounds than the ultrasonic-assisted method. Then, the other factors were investigated using monofactor analysis, i.e., extraction solvent $(30 \%, 50 \%$, and $70 \%$ aqueous methanol $(v / v)$ and pure methanol), extraction time (30 min, $45 \mathrm{~min}$, and $60 \mathrm{~min})$, and solvent volume $(5 \mathrm{~mL}, 10 \mathrm{~mL}, 15 \mathrm{~mL}$, and $20 \mathrm{~mL}$ ). As a result, the optimized extraction procedure was confirmed to be refluxed with $15 \mathrm{~mL}$ of $70 \%$ aqueous methanol solution $(v / v)$ for $45 \mathrm{~min}$.

3.2. Optimization of the Chromatographic Conditions. In order to separate the six CAs, a gradient method was developed to determine all the constituents in one analysis. Various mixtures of mobile phases were tested, such as methanol and water, methanol ( $0.1 \%$ formic acid $)$ and water ( $0.1 \%$ formic acid), and methanol ( $0.5 \%$ phosphoric acid) and water ( $0.5 \%$ phosphoric acid), but the separation was unsatisfactory. However, by replacing methanol with acetonitrile, the special mobile phase system (acetonitrile $(0.5 \%$ phosphoric acid) and water (0.5\% phosphoric acid)) significantly improved the separation. We also tried to simplify the mobile phase system as acetonitrile and water $(0.5 \%$ phosphoric acid), but the separation was unsatisfactory. Due to the similar structure, the UV absorption spectrograms of the six CAs were almost identical. The detection wavelength was selected at the maximum absorption of $327 \mathrm{~nm}$.

3.3. Method Validation. The analytical method was validated with respect to the linearity, LLOD, LLOQ, precision, repeatability, stability, and accuracy. The linear ranges, regression equations, and correlation coefficients obtained from typical calibration curves and LLOD $(S / N=3)$ and LLOQ $(S / N=10)$ are shown in Table 2. All calibration curves showed excellent linearity, and the correlation coefficients were higher than 0.999 .

As shown in Table 3, the precision of the method was evaluated with peak areas obtained for each analyte and expressed as relative standard deviation (RSD). The RSD of intraday and interday was $0.49 \%$ and $0.09 \%$ for NCA, $0.65 \%$ and $0.03 \%$ for CCA, $0.06 \%$ and $0.03 \%$ for CA, $0.10 \%$ and $0.02 \%$ for ICA, $0.03 \%$ and $0.04 \%$ for ICB, and $0.12 \%$ and $0.05 \%$ for ICC, respectively. The method is repeatable, with the RSD was in the range of $1.0 \% \sim 2.3 \%$. The CAs were proved to be stable in sample solution within $72 \mathrm{~h}$ at room temperature with the RSD below $1.1 \%$. As shown in Table 4, the extraction recoveries were performed to evaluate the accuracy of the developed method. The mean recoveries were in the range of $100.7 \% \sim 101.5 \%$ with the RSD less than $3.0 \%$ for all the six CAs. In general, the developed method is precise, repeatable, and accurate for the simultaneous quantitative determination of the six CAs in M. chamomilla.

3.4. Sample Analysis. The established method has been successfully applied for the simultaneous determination of M. chamomilla samples collected from different geographical areas, as shown in Table 5 and Figure 2. The results showed that the contents of six CAs in CMC and WHMC collected from different geographical areas were different, and the contents of six CAs in different parts of specific $M$. chamomilla were also different.

Although the position of the substituent caffeoyl group in NCA, CCA, and CA is different, their mother nucleus structures are the same. In order to simplify the results, NCA, CCA, and CA were defined as total chlorogenic acids (TCAs). Similarly, ICA, ICB, and ICC were defined as total isochlorogenic acids (TICAs). The contents of six CAs, TCAs, and TICAs in CMC were generally higher than WHMC. The TCA contents in WHMC series and CMC series were in the range of $0.17 \sim 1.98 \mathrm{mg} / \mathrm{g}$ and $0.84 \sim 3.98 \mathrm{mg} /$ $\mathrm{g}$, respectively. The TICA contents in these series were in the range of $0.47 \sim 5.84 \mathrm{mg} / \mathrm{g}$ and $1.38 \sim 9.78 \mathrm{mg} / \mathrm{g}$, respectively.

Compared with the literature report, the results showed that the contents of CAs in CMC were comparable to that of apigenin-7-O-glucoside (about $0.2 \sim 6.2 \mathrm{mg} / \mathrm{g}$ ), higher than that of most flavonoids (such as luteolin, apigenin, and 7methoxycoumarin; far less than $1.0 \mathrm{mg} / \mathrm{g}$ ) [8, 9, 23]. Because the pharmacological activities of CAs were consistent with the efficacy of CMC and WHMC, the CAs together with coumarins and flavonoids could all be considered as the main bioactive ingredients. 
TABLE 2: Linear ranges, LLOD, LLOQ, and characteristic parameters of calibration curves.

\begin{tabular}{lccccc}
\hline Name & Calibration equation & $r$ & Linear range $(\mathrm{ng})$ & LLOQ $(\mathrm{ng})$ & LLOD $(\mathrm{ng})$ \\
\hline NCA & $y=2689399 x+8525$ & 0.999 & $0.86 \sim 5.40 \times 10^{3}$ & 0.86 & 0.17 \\
CCA & $y=2557852 x+46$ & 0.999 & $0.68 \sim 4.24 \times 10^{3}$ & 0.68 & 0.14 \\
CA & $y=3178855 x-953$ & 0.999 & $0.77 \sim 4.80 \times 10^{3}$ & 0.15 \\
ICA & $y=3567273 x+9390$ & 0.999 & $0.83 \sim 5.20 \times 10^{3}$ & 0.17 \\
ICB & $y=2821879 x+1015$ & 0.999 & $0.70 \sim 4.36 \times 10^{3}$ & 0.70 & 0.14 \\
ICC & $y=3200246 x+678$ & 0.999 & $0.79 \sim 4.92 \times 10^{3}$ & 0.79 \\
\hline
\end{tabular}

Note. $y$ : peak area at $327 \mathrm{~nm} ; x$ : injection amount (ng); $r$ : correlation coefficient for 12 data points in the calibration curves $(n=2)$; LLOQ: lower limit of quantification $(S / N=10)$; LLOD: lower limit of detection $(S / N=3)$.

TABLE 3: Method validation for determination of six CAs.

\begin{tabular}{|c|c|c|c|c|}
\hline \multirow{2}{*}{ Analytes } & \multicolumn{2}{|c|}{ Precision $(n=6)($ RSD \%) } & \multirow{2}{*}{ Repeatability $(n=6)(\mathrm{RSD} \%)$} & \multirow{2}{*}{ Stability (RSD \%) } \\
\hline & Intraday & Interday & & \\
\hline NCA & 0.49 & 0.09 & 1.68 & 1.09 \\
\hline $\mathrm{CCA}$ & 0.65 & 0.03 & 2.24 & 1.09 \\
\hline $\mathrm{CA}$ & 0.06 & 0.03 & 1.28 & 0.16 \\
\hline ICA & 0.10 & 0.02 & 1.11 & 0.63 \\
\hline ICB & 0.03 & 0.04 & 1.65 & 0.35 \\
\hline ICC & 0.12 & 0.05 & 2.05 & 0.62 \\
\hline
\end{tabular}

TABle 4: Recoveries of six CAs as determined by the standard addition method $(n=6)$.

\begin{tabular}{|c|c|c|c|c|c|c|c|}
\hline Name & Sample weight (g) & Original (mg) & Spiked (mg) & Found (mg) & Recovery $^{\mathrm{a}}(\%)$ & Average recovery (\%) & RSD (\%) \\
\hline \multirow{6}{*}{ NCA } & 0.251 & 0.022 & 0.021 & 0.043 & 100.70 & \multirow{6}{*}{100.74} & \multirow{6}{*}{1.18} \\
\hline & 0.250 & 0.021 & 0.021 & 0.043 & 99.58 & & \\
\hline & 0.251 & 0.022 & 0.021 & 0.044 & 102.95 & & \\
\hline & 0.252 & 0.022 & 0.021 & 0.043 & 100.48 & & \\
\hline & 0.251 & 0.022 & 0.021 & 0.043 & 100.87 & & \\
\hline & 0.250 & 0.021 & 0.021 & 0.043 & 99.85 & & \\
\hline \multirow{6}{*}{ CCA } & 0.251 & 0.012 & 0.011 & 0.023 & 98.26 & \multirow{6}{*}{100.92} & \multirow{6}{*}{2.83} \\
\hline & 0.250 & 0.012 & 0.011 & 0.023 & 96.40 & & \\
\hline & 0.251 & 0.012 & 0.011 & 0.024 & 102.25 & & \\
\hline & 0.252 & 0.012 & 0.011 & 0.024 & 102.49 & & \\
\hline & 0.251 & 0.012 & 0.011 & 0.024 & 103.05 & & \\
\hline & 0.250 & 0.012 & 0.011 & 0.024 & 103.08 & & \\
\hline \multirow{6}{*}{ CA } & 0.251 & 0.204 & 0.204 & 0.410 & 100.84 & \multirow{6}{*}{100.77} & \multirow{6}{*}{1.09} \\
\hline & 0.250 & 0.204 & 0.204 & 0.408 & 100.10 & & \\
\hline & 0.251 & 0.205 & 0.204 & 0.415 & 102.94 & & \\
\hline & 0.252 & 0.205 & 0.204 & 0.409 & 100.28 & & \\
\hline & 0.251 & 0.205 & 0.204 & 0.409 & 100.44 & & \\
\hline & 0.250 & 0.204 & 0.204 & 0.407 & 100.05 & & \\
\hline \multirow{5}{*}{ ICA } & 0.251 & 0.410 & 0.401 & 0.815 & 100.99 & \multirow{5}{*}{101.52} & \multirow{5}{*}{1.11} \\
\hline & 0.250 & 0.409 & 0.401 & 0.813 & 100.76 & & \\
\hline & 0.251 & 0.411 & 0.401 & 0.826 & 103.57 & & \\
\hline & 0.252 & 0.411 & 0.401 & 0.815 & 100.63 & & \\
\hline & 0.251 & 0.411 & 0.401 & 0.820 & 102.08 & & \\
\hline \multirow{6}{*}{ ICB } & 0.251 & 0.128 & 0.119 & 0.248 & 101.07 & \multirow{6}{*}{101.53} & \multirow{6}{*}{0.94} \\
\hline & 0.250 & 0.128 & 0.119 & 0.248 & 101.34 & & \\
\hline & 0.251 & 0.128 & 0.119 & 0.251 & 103.17 & & \\
\hline & 0.252 & 0.128 & 0.119 & 0.249 & 101.37 & & \\
\hline & 0.251 & 0.128 & 0.119 & 0.249 & 101.92 & & \\
\hline & 0.250 & 0.127 & 0.119 & 0.246 & 100.32 & & \\
\hline \multirow{6}{*}{ ICC } & 0.251 & 0.188 & 0.175 & 0.366 & 101.89 & \multirow{6}{*}{101.55} & \multirow{6}{*}{1.06} \\
\hline & 0.250 & 0.188 & 0.175 & 0.365 & 101.52 & & \\
\hline & 0.251 & 0.189 & 0.175 & 0.369 & 103.37 & & \\
\hline & 0.252 & 0.189 & 0.175 & 0.366 & 101.59 & & \\
\hline & 0.251 & 0.188 & 0.175 & 0.364 & 100.68 & & \\
\hline & 0.250 & 0.187 & 0.175 & 0.362 & 100.26 & & \\
\hline
\end{tabular}

Note. ${ }^{\text {a }}$ Recovery $(\%)=[($ found-original $) /$ spiked $] \times 100$; RSD: relative standard deviation. 
TABLE 5: Heatmap of six CA contents in M. chamomilla samples $(n=2)$.

\begin{tabular}{|c|c|c|c|c|c|c|c|c|}
\hline \multirow{2}{*}{ Sample lists } & \multicolumn{8}{|c|}{ Content $(\mathrm{mg} / \mathrm{g})$} \\
\hline & NCA & CCA & CA & ICA & $\mathrm{ICB}$ & ICC & TCAs & TICAs \\
\hline D1 & 0.059 & 0.045 & 0.289 & 0.826 & 0.390 & 0.466 & 0.393 & 1.681 \\
\hline D3 & 0.117 & 0.076 & 1.306 & 3.360 & 1.093 & 1.384 & 1.499 & 5.837 \\
\hline $\mathrm{D} 4$ & 0.118 & 0.028 & 0.667 & 0.940 & 0.164 & 0.282 & 0.813 & 1.386 \\
\hline D5 & 0.040 & 0.031 & 0.216 & 0.584 & 0.310 & 0.334 & 0.287 & 1.228 \\
\hline D6 & 0.037 & 0.030 & 0.446 & 1.107 & 0.454 & 0.501 & 0.513 & 2.061 \\
\hline D7 & 0.060 & 0.061 & 0.437 & 0.971 & 0.329 & 0.546 & 0.558 & 1.846 \\
\hline D8 & 0.031 & 0.021 & 0.119 & 0.395 & 0.157 & 0.166 & 0.171 & 0.718 \\
\hline D9 & 0.259 & 0.164 & 1.206 & 0.807 & 0.150 & 0.346 & 1.629 & 1.303 \\
\hline D10 & 0.409 & 0.049 & 1.526 & 1.364 & 0.466 & 0.588 & 1.984 & 2.418 \\
\hline D11 & 0.084 & 0.017 & 0.218 & 0.469 & 0.137 & 0.263 & 0.320 & 0.869 \\
\hline D12 & 0.124 & 0.009 & 0.181 & 0.228 & 0.052 & 0.187 & 0.313 & 0.467 \\
\hline $\mathrm{H} 1$ & 0.211 & 0.173 & 2.706 & 4.445 & 0.541 & 2.102 & 3.090 & 7.088 \\
\hline $\mathrm{H} 2$ & 0.386 & 0.180 & 1.837 & 2.411 & 1.912 & 1.879 & 2.403 & 6.202 \\
\hline H3 & 0.406 & 0.273 & 1.652 & 1.786 & 2.395 & 2.481 & 2.330 & 6.662 \\
\hline $\mathrm{H} 4$ & 0.401 & 0.157 & 1.951 & 1.923 & 1.649 & 1.706 & 2.509 & 5.278 \\
\hline H5 & 0.415 & 0.206 & 1.374 & 1.615 & 2.389 & 2.239 & 1.995 & 6.243 \\
\hline H6 & 0.325 & 0.170 & 0.994 & 0.847 & 1.107 & 1.281 & 1.488 & 3.236 \\
\hline $\mathrm{H} 7$ & 0.314 & 0.240 & 2.398 & 1.523 & 1.596 & 1.527 & 2.952 & 4.646 \\
\hline $\mathrm{H} 8$ & 0.403 & 0.183 & 1.180 & 1.196 & 1.023 & 1.269 & 1.766 & 3.488 \\
\hline H9 & 0.350 & 0.226 & 1.686 & 1.525 & 1.616 & 1.900 & 2.263 & 5.041 \\
\hline $\mathrm{H} 10$ & 0.529 & 0.251 & 1.501 & 2.095 & 1.851 & 2.496 & 2.281 & 6.441 \\
\hline H11 & 0.557 & 0.339 & 3.081 & 2.529 & 2.451 & 2.802 & 3.976 & 7.783 \\
\hline H12 & 0.726 & 0.227 & 1.703 & 4.615 & 1.996 & 3.171 & 2.656 & 9.782 \\
\hline H13 & 0.145 & 0.043 & 0.662 & 0.284 & 0.440 & 0.660 & 0.850 & 1.384 \\
\hline $\mathrm{H} 14$ & 0.389 & 0.047 & 0.400 & 0.398 & 0.538 & 0.828 & 0.837 & 1.764 \\
\hline D1 roots & 0.082 & 0.050 & 0.418 & 0.860 & 0.383 & 0.653 & 0.550 & 1.896 \\
\hline D1 stems & 0.038 & 0.024 & 0.167 & 0.493 & 0.220 & 0.256 & 0.229 & 0.970 \\
\hline D1 leaves & 0.045 & 0.040 & 0.135 & 0.229 & 0.147 & 0.188 & 0.220 & 0.564 \\
\hline D10 roots & 0.086 & 0.045 & 0.815 & 1.603 & 0.474 & 0.698 & 0.946 & 2.776 \\
\hline D10 stems & 0.201 & 0.024 & 0.876 & 0.699 & 0.168 & 0.301 & 1.101 & 1.167 \\
\hline D10 leaves & 1.683 & 0.088 & 4.086 & 5.152 & 0.706 & 2.289 & 5.857 & 8.147 \\
\hline D12 roots & 0.022 & 0.005 & 0.038 & 0.105 & 0.032 & 0.065 & 0.064 & 0.202 \\
\hline D12 stems & 0.081 & 0.007 & 0.092 & 0.149 & 0.054 & 0.153 & 0.180 & 0.356 \\
\hline D12 leaves & 0.180 & 0.009 & 0.212 & 0.247 & 0.069 & 0.282 & 0.402 & 0.599 \\
\hline
\end{tabular}

Note. The deeper the green, the lower the content; the deeper the red, the higher the content.

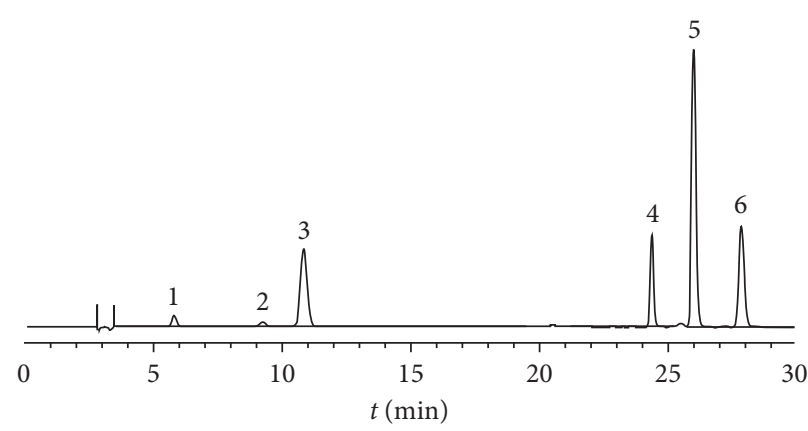

(a)

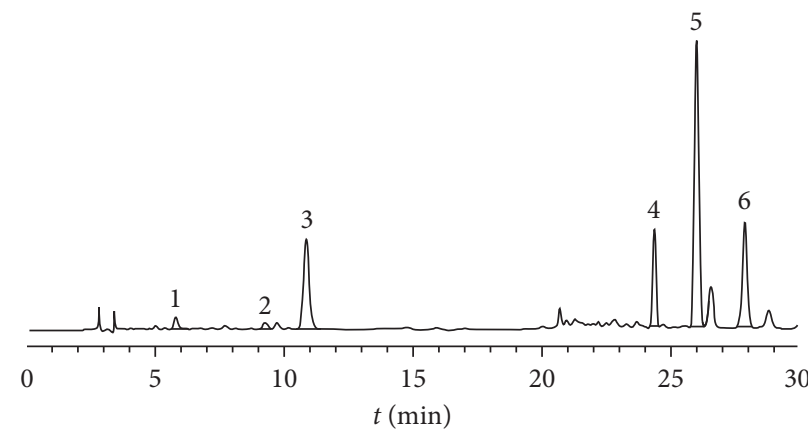

(b)

FIGURE 2: HPLC chromatograms of the (a) standard mix stock solution and (b) sample (D10 roots). 1, NCA; 2, CCA; 3, CA; 4, ICB; 5, ICA; 6, ICC. 


\section{Conclusion}

In this work, an HPLC method was established for the simultaneous determination of six CAs with pharmacological activities in M. chamomilla for the first time. The established method was validated by linearity, reproducibility, recovery, and precision; all parameters found satisfactory. This newly established HPLC method will be helpful in the quality assessment of CMC, WHMC, and related herbal formulas in future.

\section{Data Availability}

The chromatographic data used to support the findings of this study are included within the article.

\section{Conflicts of Interest}

The authors declare that there are no conflicts of interest.

\section{Acknowledgments}

This work was financially supported by the Key Project at Central Government Level: The Ability Establishment of Sustainable Use for Valuable Chinese Medicine Resources (2060302). The authors are grateful to Dr. Rizwan Elahi for providing language assistance and grammar check.

\section{References}

[1] O. Singh, Z. Khanam, N. Misra, and M. Srivastava, "Chamomile (Matricaria chamomilla L.): an overview," Pharmacognosy Reviews, vol. 5, no. 9, p. 82, 2011.

[2] V. Gupta, P. Mittal, P. Bansal, S. L. Khokra, and D. Kaushik, "Pharmacological potential of Matricaria recutita-a review," International Journal of Pharmaceutical Sciences and Drug Research, vol. 2, no. 1, pp. 12-16, 2010.

[3] World Health Organization, WHO Monographs on Selected Medicinal Plants, vol. 1, World Health Organization, Geneva,Switzerland, 1999.

[4] Chinese Materia Medica Editorial Board, Shanghai Scientific and Technical Publishers, Shanghai, China, 2005.

[5] J. K. Srivastava, E. Shankar, and S. Gupta, "Chamomile: a herbal medicine of the past with a bright future (review)," Molecular Medicine Reports, vol. 3, no. 6, pp. 895-901, 2010.

[6] J. Exner, J. Reichling, T. Cole, and H. Becker, "Methylated flavonoid-aglycones from "Matricariae flos"," Planta Medica, vol. 41, no. 2, pp. 198-200, 1981.

[7] V. Petrulová-Poracká, M. Repčák, M. Vilková, and J. Imrich, "Coumarins of Matricaria chamomilla L.: aglycones and glycosides," Food Chemistry, vol. 141, no. 1, pp. 54-59, 2013.

[8] X.-Y. Xie, F.-F. Chen, and Y.-P. Shi, "Simultaneous determination of eight flavonoids in the flowers of Matricaria chamomilla by high performance liquid chromatography," Journal of AOAC International, vol. 97, no. 3, pp. 778-783, 2014.

[9] G. Haghi, A. Hatami, A. Safaei, and M. Mehran, "Analysis of phenolic compounds in Matricaria chamomilla and its extracts by UPLC-UV," Research in Pharmaceutical Sciences, vol. 9, no. 1, pp. 31-37, 2014.

[10] M. H. Fu, Z. J. Wang, H. J. Yang et al., “A new $\mathrm{C}_{21}$-steroidal glycoside from Cynanchum stauntonii," Chinese Chemical Letters, vol. 18, no. 4, pp. 415-417, 2007.
[11] D. Zhang, S.-B. Li, L. Yang et al., "Two new C-methyl flavanones from the rhizomes and frond bases ofMatteuccia struthiopteris," Journal of Asian Natural Products Research, vol. 15, no. 11, pp. 1163-1167, 2013.

[12] C.-X. Liang, Y.-X. Cao, D. Zhang, K. Zhang, and L. Yang, "A new neoclerodane diterpenoid from Scutellaria barbata," Chinese Traditional and Herbal Drugs, vol. 46, no. 19, pp. 2843-2845, 2015.

[13] Z. Yifan, D. Zhang, C.-X. Liang et al., "Chemical constituents from Matricaria chamomilla L. (I)," Journal of Chinese Pharmaceutical Sciences, vol. 27, no. 5, pp. 324-331, 2018.

[14] Y. Maruta, J. Kawabata, and R. Niki, "Antioxidative caffeoylquinic acid derivatives in the roots of burdock (Arctium lappa L.)," Journal of Agricultural and Food Chemistry, vol. 43, no. 10, pp. 2592-2595, 1995.

[15] Y. Kimura, H. Okuda, T. Okuda, T. Hatano, and S. Arichi, "Studies on the activities of tannins and related compounds, $\mathrm{X}$. Effects of caffeetannins and related compounds on arachidonate metabolism in human polymorphonuclear leukocytes," Journal of Natural Products, vol. 50, no. 3, pp. 392-399, 1987.

[16] G. Peluso, V. De Feo, F. De Simone, E. Bresciano, and M. L. Vuotto, "Studies on the inhibitory effects of caffeoylquinic acids on monocyte migration and superoxide ion production," Journal of Natural Products, vol. 58, no. 5, pp. 639-646, 1995.

[17] X. Zhu, H. Zhang, and R. Lo, "Phenolic compounds from the leaf extract of artichoke (Cynara scolymusL.) and their antimicrobial activities," Journal of Agricultural and Food Chemistry, vol. 52, no. 24, pp. 7272-7278, 2004.

[18] H. Oh, D.-G. Kang, S. Lee, and H.-S. Lee, "Angiotensin converting enzyme inhibitors from Cuscuta japonica Choisy," Journal of Ethnopharmacology, vol. 83, no. 1-2, pp. 105-108, 2002.

[19] T. Xiang, Q.-B. Xiong, A. I. Ketut et al., "Studies on the hepatocyte protective activity and the structure-activity relationships of quinic acid and caffeic acid derivatives from the flower buds of Lonicera bournei," Planta Medica, vol. 67, no. 4 , pp. 322-325, 2001.

[20] W.-C. Chang and F.-L. Hsu, "Inhibition of platelet activation and endothelial cell injury by polyphenolic compounds isolated from Lonicera japonica Thunb," Prostaglandins, Leukotrienes and Essential Fatty Acids, vol. 45, no. 4, pp. 307-312, 1992.

[21] Y.-R. Sun, J.-X. Dong, Q.-J. Lv et al., "Effects of dicaffeoylquinic acid against liver fibrosis and lipid peroxidation in rats: an experimental study," Bulletin of the Academy of Military Medical Sciences, vol. 26, no. 1, pp. 39-42, 2002.

[22] J.-P. Zuo, W.-M. Zhao, Y.-F. Yang, and P.-G. He, "Composition of chlorogenic acid and isochlorogenic acid and its medical application," C. N. Patent 1,449,753, field June 2, 2003 and issued October 22, 2003.

[23] J.-G. Li, S.-L. Han, D.-S. Zhao, H.-B. Zhang, J. Geng, and X.-X. Li, "Determination of five compounds from two species of Chamomiles from Xinjiang by QAMS," Herald of Medicine, vol. 33, no. 11, pp. 1491-1495, 2004. 

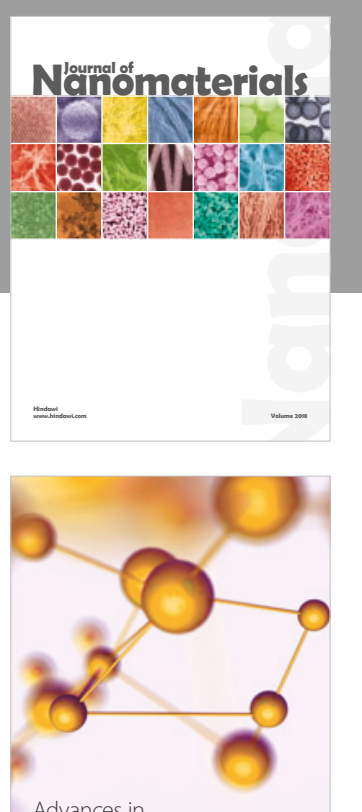

Physical Chemistry
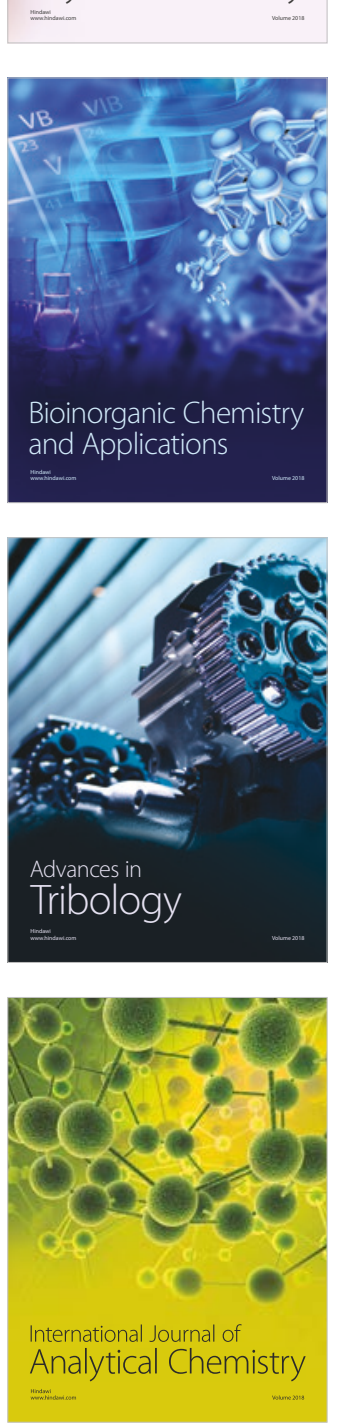

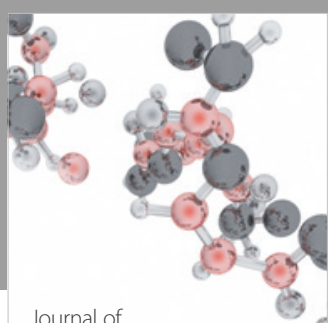

Analytical Methods

in Chemistry

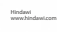

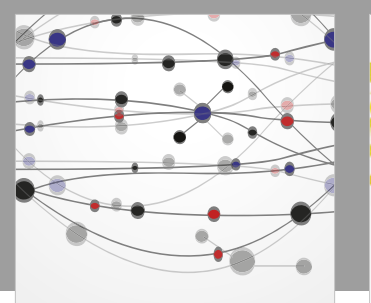

The Scientific World Journal

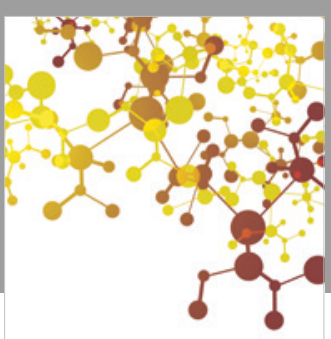

Journal of

Applied Chemistry
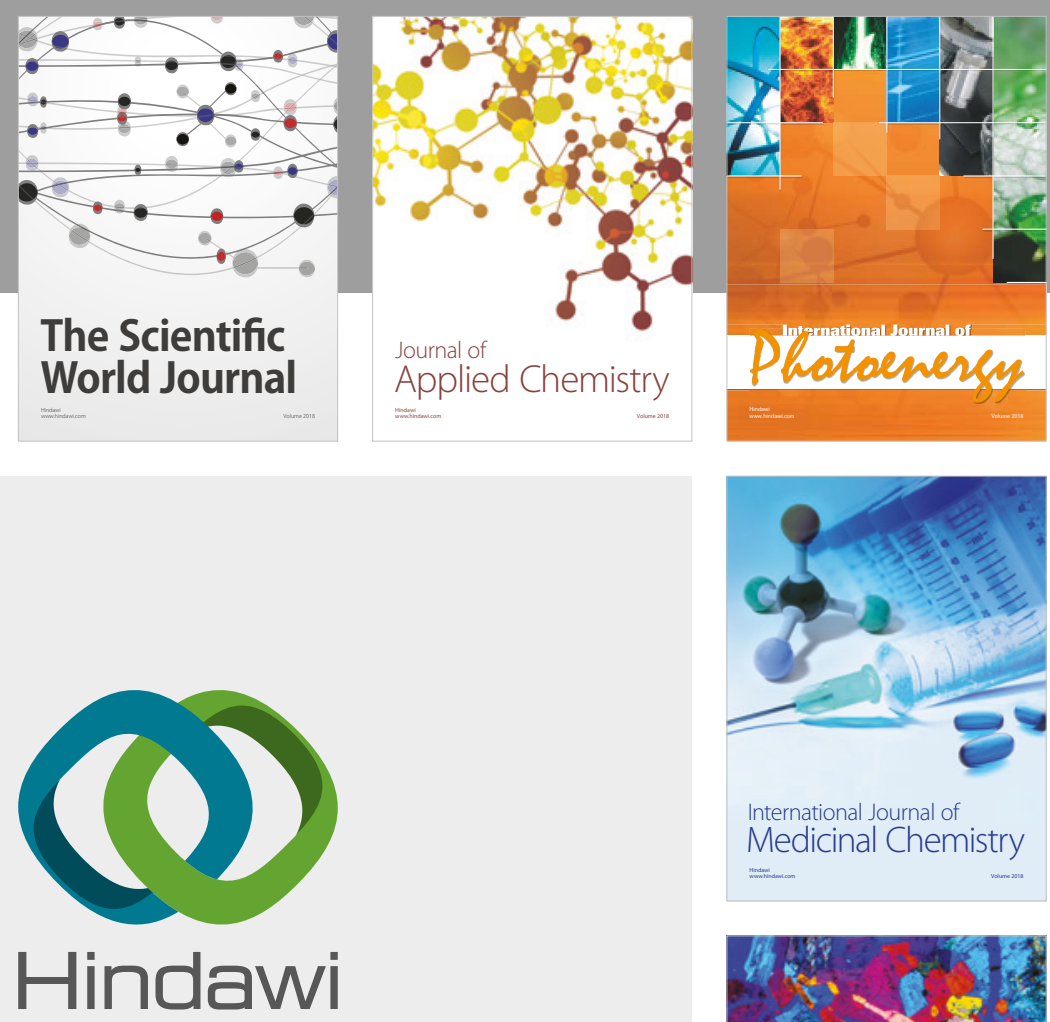

Submit your manuscripts at

www.hindawi.com
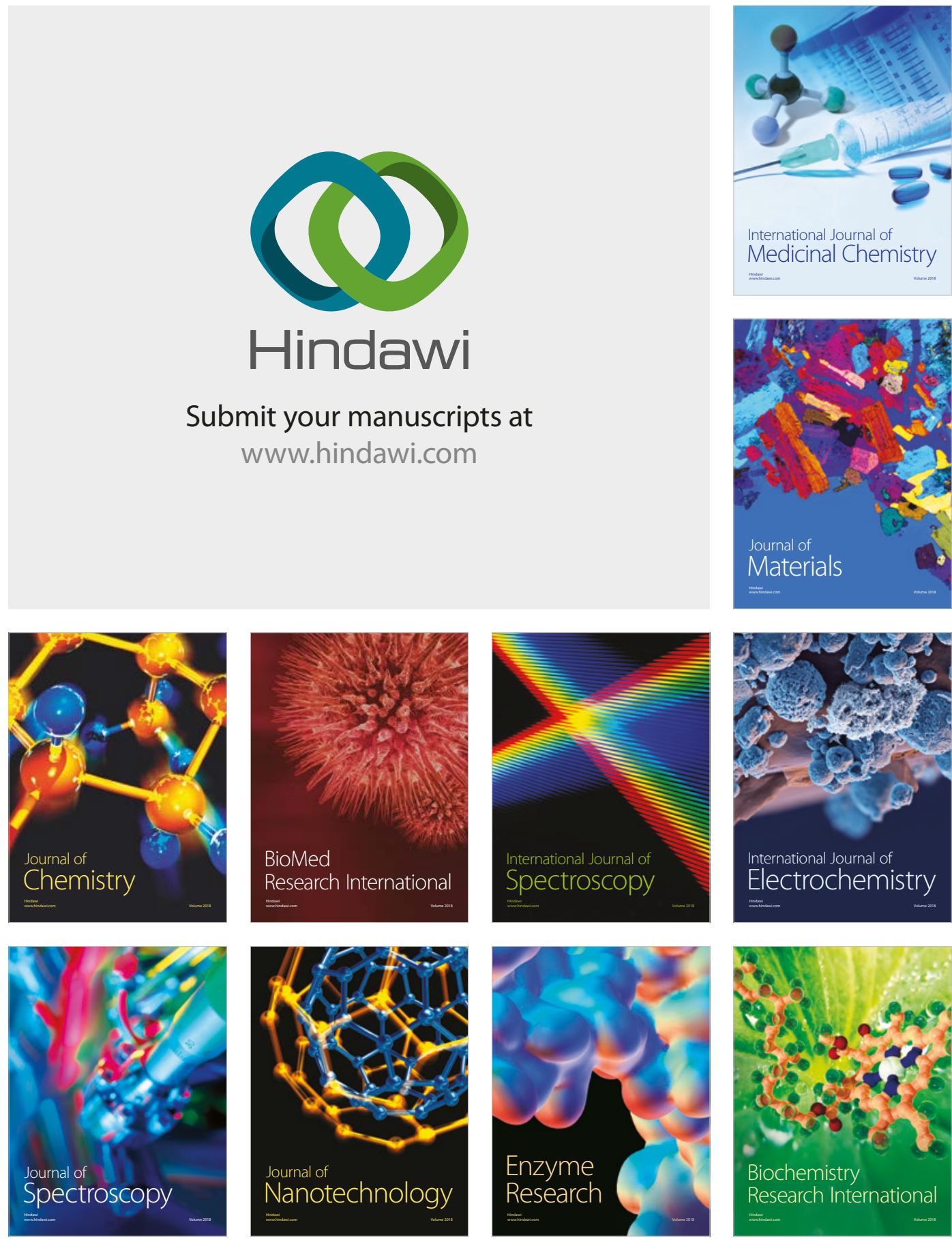
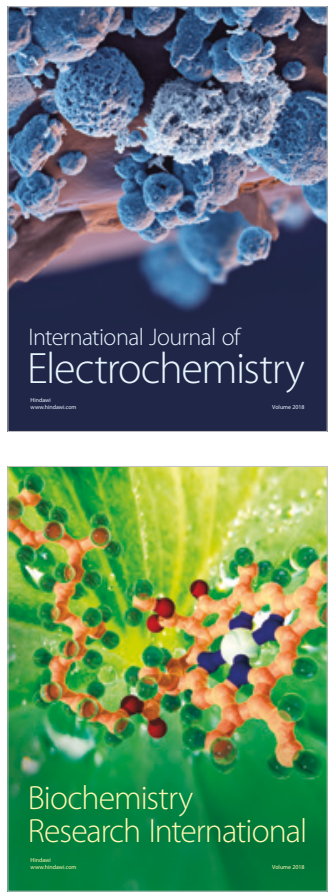